\title{
Efficient Gene Knockout in the Maize Pathogen Setosphaeria turcica Using Agrobacterium tumefaciens-Mediated Transformation
}

\author{
Chunsheng Xue, Dongliang Wu, Bradford J. Condon, Qing Bi, Weiwei Wang, and B. Gillian Turgeon
}

First author: Department of Plant Pathology and Plant-Microbe Biology, Cornell University, Ithaca, NY 14853 and College of Plant Protection, Shenyang Agricultural University, Shenyang 110161, China; second, third, fourth, fifth, and sixth authors: Department of Plant Pathology and Plant-Microbe Biology, Cornell University; fourth author: State Key Program of Microbiology and Department of Microbiology, College of Life Sciences, Nankai University, Tianjin 300071, China; and fifth author: College of Plant Science, Jilin University, Changchun 130062, China.

Accepted for publication 17 January 2013

\begin{abstract}
Xue, C., Wu, D., Condon, B. J., Bi, Q., Wang, W., and Turgeon, B. G. 2013. Efficient gene knockout in the maize pathogen Setosphaeria turcica using Agrobacterium tumefaciens-mediated transformation. Phytopathology 103:641-647.

Setosphaeria turcica, a hemibiotrophic pathogenic dothideomycete, is the causal agent of Northern Leaf Blight of maize, which periodically causes significant yield losses worldwide. To explore molecular mechanisms of fungal pathogenicity and virulence to the host, an efficient

terials, incubation time, induction medium type, Agrobacterium cell density, and method of co-incubation were optimized for deletion of $1,3,8$ trihydroxynaphthalene reductase, a gene in the melanin biosynthesis pathway, as a test case. Four additional genes were deleted in two different $S$. turcica field isolates to confirm robustness of the method. One of these mutant strains was reduced in virulence compared with the wildtype strain when inoculated on susceptible maize. Transformation efficiency was $\approx 20 \pm 3$ transformants per $1 \times 10^{6}$ germlings and homologous recombination efficiency was 33.3 to $100 \%$.
\end{abstract} targeted gene knockout transformation system using Agrobacterium tumefaciens was established with field collected strains. The starting ma-
Additional keyword: ECP6.
Setosphaeria turcica, a hemibiotrophic pathogenic Dothideomycete, is the causal agent of Northern Leaf Blight (NLB) of maize, one of the most serious maize foliar diseases impacting yield in warm and humid regions $(6,23)$. To date, at least seven races of the fungus have been identified. As with all hemibiotrophs (and biotrophs), gene-for-gene interactions between plant and pathogen are expected to be continually evolving and, as new fungal effector molecules (secreted disease factors) are deployed, the host responds with new or modified plant resistance genes. In recent years, new races of $S$. turcica have emerged which overcome common sources of NLB resistance, and NLB is once again in focus as a major constraint to worldwide maize production (6).

The genus Setosphaeria is an important group of species that includes pathogens of monocots such as S. turcica and the additional maize pathogen, $S$. rostrata (causal agent of rostratum leaf spot and apparent agent of the recent spinal meningitis outbreak). The genus Setosphaeria is sister to the related maize pathogen Cochliobolus heterostrophus and to the wheat pathogens Pyrenophora tritici-repentis and Mycosphaerella graminicola, all of which have been sequenced (http://genome.jgi.doe.gov/ programs/fungi/index.jsf). Recently, S. turcica field strain Et28A (race 23N) was sequenced (http://genome.jgi.doe.gov/Settu1/ Settu1.home.html), which provides an opportunity for in-depth understanding of virulence requirements of the fungus to its host, maize. Lacking however, until this report, are targeted gene-

Corresponding author: B. G. Turgeon; E-mail address: bgt1@ cornell.edu

* The $\boldsymbol{e}$-Xtra logo stands for "electronic extra" and indicates that the online version contains one supplemental figure and one supplemental table. Figures 2, 3, and 6 appear in color online.

http://dx.doi.org/10.1094/PHYTO-08-12-0199-R

(C) 2013 The American Phytopathological Society deletion protocols for this fungus needed to assess candidate genes for involvement in mechanisms of pathogenicity to plants. This is especially critical for testing mutants of field isolates representing the various races of the fungus on susceptible and resistant plants.

Protoplast-polyethylene glycol (PEG)-based transformation and Agrobacterium tumefaciens-mediated transformation (ATMT) are two major methods for deleting fungal genes by homologous recombination. The protoplast-PEG-mediated transformation approach has been used with many important plant-pathogenic fungi $(7,13,14,21,25,27,30)$; however, for some fungi, low yield and low viability of protoplasts are limiting $(3,19)$. Our unsuccessful attempts at transformation of S. turcica (see Results) are likely attributable to this constraint. Targeted gene knockout by protoplast-PEG-based transformation has been reported in three thesis publications on $S$. turcica $(4,11,31)$ but efficiency was $<1 \%$. ATMT has been used successfully with many fungi as an alternative to protoplasting $(9,18)$. With ATMT, it is often possible to choose one or more developmental stages, such as germinating conidia, fresh mycelia, or fruiting bodies, as starting materials for transformation (28). Random insertion mutations have been reported for $S$. turcica using ATMT $(8,15)$; however, high-efficiency transformation with targeted gene disruption has not been established to date.

In this study, we first attempted transformation by protoplasting several $S$. turcica field isolates representing different races but had no success, then focused on evaluating factors influencing efficiency of gene knockout by ATMT. For this, we choose the 1,3,8trihydroxynaphthalene reductase $(3 H N R)$ gene as a target. $3 \mathrm{HNR}$ reduces 1,3,8-trihydroxynaphthalene to vermelone, which is then dehydrated, dimerized, and polymerized to form 1,8-dihydroxynaphthalene-type melanin, making it a useful indicator of targeted gene knockout, because mutants can be easily identified by an alteration in pigmentation (29). Deletion of $3 H N R$ did not alter 
virulence of the corresponding mutant on susceptible maize. Upon success with transformation, we then confirmed the robustness of our method by using it to delete four additional genes in two different undomesticated strains. Deletion of the ECP6 gene, encoding a lysine motif protein used as an effector by some fungi $(2,17)$, caused a reduction in virulence to maize compared with the wild-type (WT) strain.

\section{MATERIALS AND METHODS}

Fungal strains, culture conditions, and harvesting conidia. S. turcica strains Et100-1A, Et86A, EtNY001, Et10A, Et28A, and 52B obtained from R. Nelson at Cornell University were tested for sensitivity to hygromycin B and ability to be protoplasted. Strain Et28A (race 23N) was chosen initially for transformation attempts, based on drug sensitivity (described in Results). Fungal strains were stored as single conidial cultures at $-80^{\circ} \mathrm{C}$ in lactose casein (LC) medium (37.5 g of lactose, $3.0 \mathrm{~g}$ of casein, $0.5 \mathrm{~g}$ of $\mathrm{MgSO}_{4}$, and $1.0 \mathrm{~g}$ of $\mathrm{KH}_{2} \mathrm{PO}_{4}$ per liter] in $25 \%$ glycerol. For each

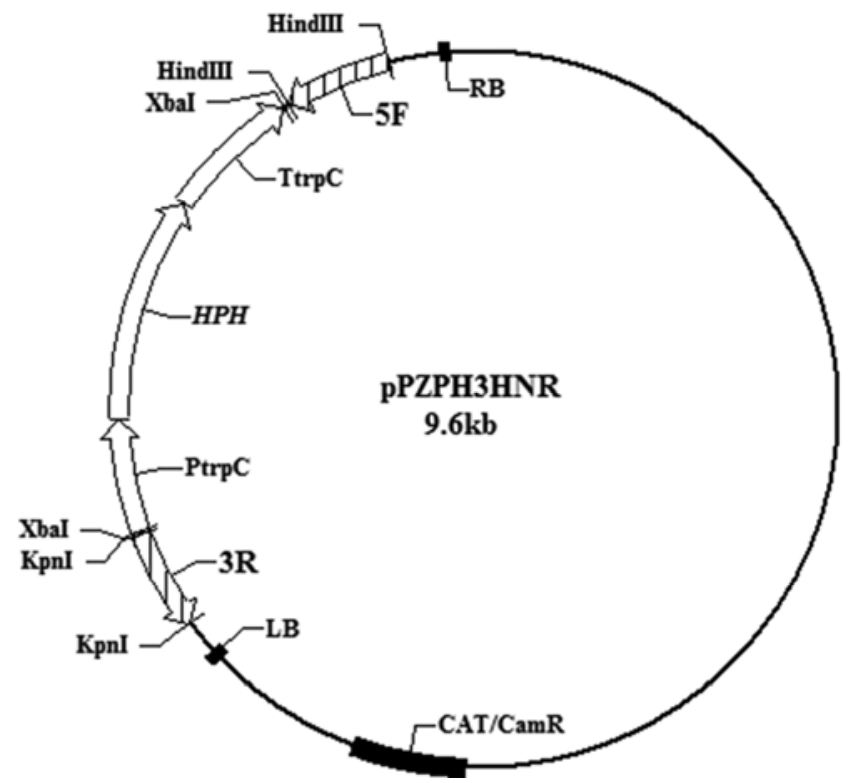

Fig. 1. Agrobacterium tumefaciens-mediated transformation transformation plasmid for 1,3,8-trihydroxynaphthalene reductase $(3 H N R)$ gene knockout. Restriction map of pPZPH3HNR, a binary vector for deletion of Setosphaeria turcica $3 H N R$ gene. $\mathrm{CAT}=$ chloramphenicol acetyl transferase; CamR = chloramphenicol resistance gene for selection in bacteria. The XbaI site was used for insertion of the hygromycin B resistance cassette $(H P H)$. PtrpC and TtrpC are the promoter and terminator regions of the TrpC gene from Aspergillus nidulans. 3HNR-5F (upstream flanking sequence) was inserted as a HindIII fragment between the $H P H$ cassette and the T-DNA right border (RB), while $3 \mathrm{HNR}-3 \mathrm{R}$ (downstream flanking sequence) was inserted as KpnI fragment between the $H P H$ cassette and the left border (LB). experiment, an aliquot was recovered from glycerol and transferred to LC agar (LCA) for 12 to 14 days at $25^{\circ} \mathrm{C}$ in $12 \mathrm{~h}$ light and $12 \mathrm{~h}$ of darkness. To harvest conidia, sterile distilled $\mathrm{H}_{2} \mathrm{O}$ was added to LCA plates, the surface was rubbed with a rubber policeman to dislodge conidia, and the resulting conidial suspension was filtered through two layers of cheesecloth to remove mycelial debris.

Construction of a plasmid for Agrobacterium transformation. The 2,113-bp $H P H$ cassette for resistance to hygromycin $\mathrm{B}$ was isolated by digesting pUCATPH (16) with $\mathrm{XbaI}$ and cloned into the binary vector pPZP100 (12), precut with XbaI; the resulting plasmid was named pPZPH. Portions of the $3 H N R$ gene, 3HNR-5F (469 bp) and 3HNR-3R (414 bp), were amplified by polymerase chain reaction (PCR) with primers $3 \mathrm{HNR}-\mathrm{F}_{1} / \mathrm{R}_{1}$ and $3 \mathrm{HNR}-\mathrm{F}_{2} / \mathrm{R}_{2}$, respectively, using Phusion DNA polymerase (New England Biolabs, Ipswich, MA). HindIII restriction enzyme recognition sites were added to the $5^{\prime}$ ends of the $3 H N R-F_{1} / R_{1}$ primers and $K p n I$ restriction enzyme recognition sites were added to the $5^{\prime}$ ends of $3 \mathrm{HNR}-\mathrm{F}_{2} / \mathrm{R}_{2}$ primers. These two PCR products were then inserted, separately, into the TOPO vector (Life Technologies, Carlsbad, CA), giving rise to plasmids TOPO-5F and TOPO-3R. The 3HNR-5F fragment was cut from TOPO-5F with HindIII and ligated into pPZPH, precut with HindIII, to generate pPZPH5F. The 3HNR-3R fragment was cut from TOPO3R using $K p n \mathrm{I}$ and ligated into pPZPH5F precut with $K p n \mathrm{I}$. The final plasmid was named pPZPH3HNR (Fig. 1). Insertion orientation was determined by PCR using primers 3HNR$\mathrm{F}_{1} /$ TtrpCend and PtrpC/3HNR-R 2 . pPZPH3HNR was transformed into A. tumefaciens strain AGL-1 by the freeze-thaw method (1). Primer sequences are shown in Table 1.

Four additional $S$. turcica genes-LAE1, encoding a transcriptional regulator of secondary metabolite genes; PKS179218, encoding a polyketide synthase; ECP6, encoding a lysine motif protein used as an effector by some fungi; and FTRl, encoding an iron permease-were deleted using the one-step construction of Agrobacterium-recombination-ready-plasmids (OSCAR) method to construct the transformation plasmids (21) which were transformed into AGL-1 by the same method mentioned below (1). Primers are listed in Supplementary Table 1 and lengths of $5^{\prime}$ and $3^{\prime}$ flanking sequences used in constructions for each gene are listed in Table 2.

Transformation of $\boldsymbol{S}$. turcica. A. tumefaciens strain AGL-1, containing pPZPH3HNR or the OSCAR plasmids, was grown at $28^{\circ} \mathrm{C}$ for 1 day in Luria broth (LB) $(5 \mathrm{ml})$, supplemented with chloramphenicol $(50 \mu \mathrm{g} / \mathrm{ml})$ or spectinomycin $(100 \mu \mathrm{g} / \mathrm{ml})$ for OSCAR plasmids, and ampicillin $(100 \mu \mathrm{g} / \mathrm{ml})$. The culture was diluted with Agrobacterium induction medium (IAM) to an optical density at $600 \mathrm{~nm}\left(\mathrm{OD}_{600}\right)=0.15$ in a final volume of $5 \mathrm{ml}$. IAM (5) is $10 \mathrm{ml}$ of potassium phosphate buffer $(1 \mathrm{M}, \mathrm{pH}$ 5.3), $20 \mathrm{ml}$ of $\mathrm{MN}$ buffer $\left(\mathrm{MgSO}_{4} \cdot 7 \mathrm{H}_{2} \mathrm{O}\right.$ at $30 \mathrm{~g} / \mathrm{liter}$ and $\mathrm{NaCl}$ at $15 \mathrm{~g} /$ liter), $1 \mathrm{ml}$ of $1 \% \mathrm{CaCl}_{2} \cdot 2 \mathrm{H}_{2} \mathrm{O}, 10 \mathrm{ml}$ of $0.01 \% \mathrm{FeSO}_{4}, 5 \mathrm{ml}$ of spore elements $\left(\mathrm{ZnSO}_{4} \cdot 7 \mathrm{H}_{2} \mathrm{O}\right.$ at $100 \mathrm{mg} / \mathrm{liter}, \mathrm{CuSO}_{4} \cdot 5 \mathrm{H}_{2} \mathrm{O}$

TABLE 1. Oligonucleotides used in targeted deletion of 1,3,8-trihydroxynaphthalene reductase (3HNR)

\begin{tabular}{|c|c|c|}
\hline Name & Description $^{\mathrm{a}}$ & Sequence $\left(5^{\prime}-3^{\prime}\right)^{\mathrm{b}}$ \\
\hline $3 \mathrm{HNR}_{-} \mathrm{F}_{1}$ & Forward primer of $3 H N R$ upstream flank sequence & gccaagcttATGGCCAACATCGAGCAAAC \\
\hline $3 \mathrm{HNR}-\mathrm{R}_{1}$ & Reverse primer of $3 H N R$ upstream flank sequence & gccaagcttACTTCCATGCGCTTGTAGG \\
\hline $3 \mathrm{HNR}-\mathrm{F}_{2}$ & Forward primer of $3 H N R$ downstream flank sequence & gccggtaccGTGGCCGCATCATCCTCA \\
\hline $3 \mathrm{HNR}-\mathrm{R}_{2}$ & Reverse primer of $3 H N R$ downstream flank sequence & gecggtaccTGACCTTTCCGTTGACCCAG \\
\hline $3 \mathrm{HNR}-\mathrm{F}_{3}$ & Forward primer upstream of $3 H N R$ upstream flank & CGACCCAATCCCAAACACAA \\
\hline $3 \mathrm{HNR}-\mathrm{R}_{3}$ & Reverse primer downstream of $3 H N R$ downstream flank & AGGCAGCACCGTCAATACCA \\
\hline PtrpC & Reverse primer of $\operatorname{Tr} p C$ promoter & GGTCGTTCACTTACCTTGCTTG \\
\hline TtrpCend & Forward primer of $\operatorname{Trp} C$ terminator & GTGAATGCTCCGTAACACCCAATAC \\
\hline NLC37 & $H P H$ gene & GGATGCCTCCGCTCGAAGTA \\
\hline NLC38 & $H P H$ gene & CGTTGCAAGACCTGCCTGAA \\
\hline M13R & Vector sequence in pUCATPH (16) & AGCGGATAACAATTTCACACAGGA \\
\hline
\end{tabular}

a $\operatorname{Trp} C$ is a tryptophan biosynthesis gene from Aspergillus nidulans.

b Lowercase letters are restriction enzyme recognition sites added to the primers. 
at $100 \mathrm{mg} / \mathrm{liter}, \mathrm{H}_{3} \mathrm{BO}_{3}$ at $100 \mathrm{mg} / \mathrm{liter}, \mathrm{MnSO}_{4} \cdot \mathrm{H}_{2} \mathrm{O}$ at 100 $\mathrm{mg} / \mathrm{liter}$, and $\mathrm{Na}_{2} \mathrm{MoO}_{4} \cdot 2 \mathrm{H}_{2} \mathrm{O}$ at $100 \mathrm{mg} / \mathrm{liter}$ ), $2.5 \mathrm{ml}$ of $20 \%$ $\mathrm{NH}_{4} \mathrm{NO}_{3}, 10 \mathrm{ml}$ of $50 \%$ glycerol ( $\mathrm{vol} / \mathrm{vol}$ ), $40 \mathrm{ml}$ of $1 \mathrm{M} \mathrm{MES}$

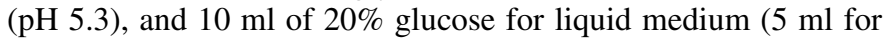
solid medium) in a 1-liter volume (containing the same concentrations of antibiotics as LB), plus acetosyringone (AS) (200 to $500 \mu \mathrm{g} / \mathrm{ml}$ ). Cultures were grown to $\mathrm{OD}_{600}=0.2$ to 0.6. An Et28A conidial suspension $\left(5 \mathrm{ml}\right.$ at $\left.1 \times 10^{6} / \mathrm{ml}\right)$ was germinated in 100 $\mathrm{ml}$ of Fries medium (23) in a 250-ml flask, for $0,2,6,12,18$, or $24 \mathrm{~h}$ before mixing with an equal volume of induced AGL-1 cells in a $50-\mathrm{ml}$ falcon centrifuge tube. The mixture $(500 \mu \mathrm{l})$ was placed on a cellulose nitrate membrane (Whatman, $0.45 \mu \mathrm{m}$ ) on top of IAM agar (15 g/liter) or induction medium (IM) agar (15 g/liter) in the presence of AS $(200,300,400$, or $500 \mu \mathrm{M})$ and incubated at $25^{\circ} \mathrm{C}$ for $48 \mathrm{~h}$. IM (8) (in 1 liter) is $10.5 \mathrm{~g}$ of $\mathrm{K}_{2} \mathrm{HPO}_{4}, 4.5 \mathrm{~g}$ of $\mathrm{KH}_{2} \mathrm{PO}_{4}, 1.0 \mathrm{~g}$ of $\mathrm{NH}_{4} \mathrm{SO}_{4}, 0.5 \mathrm{~g}$ of $\mathrm{Na}_{3}$ citrate $\cdot 2 \mathrm{H}_{2} \mathrm{O}, 0.2 \mathrm{~g}$ of $\mathrm{MgSO}_{4} \cdot 7 \mathrm{H}_{2} \mathrm{O}, 1 \mathrm{mg}$ of thiamine- $\mathrm{HCl}, 2 \mathrm{~g}$ of glucose, $40 \mathrm{mM}$ MES, and $0.5 \%$ glycerol, pH 5.3 (containing the same concentrations of antibiotics as AS and IAM). Membranes were transferred onto LCA plates containing cefotaxime $(200 \mu \mathrm{g} / \mathrm{ml})$ and hygromycin B $(100 \mu \mathrm{g} / \mathrm{ml})$ to kill Agrobacterium cells and select for candidate transformants, respectively. Plates were incubated at $25^{\circ} \mathrm{C}$ for 7 to 12 days until conidiogenesis. Candidate transformants were purified by isolating single conidia and reselecting on LCA medium containing the same concentrations of hygromycin B and cefotaxime. Purified hygromycin Bresistant candidate transformants were stored in LC in $25 \%$ glycerol at $-80^{\circ} \mathrm{C}$.

DNA isolation and confirmation of gene deletion. For $3 \mathrm{HNR}$, genomic DNA was extracted from candidate transformants grown on LCA plates using the Ultraclean Microbial DNA Isolation kit (MOBIO, Carlsbad, CA). PCR evaluation to confirm $3 H N R$ gene

TABLE 2. Transformation and targeted deletion statistics for five Setosphaeria turcica genes

\begin{tabular}{|c|c|c|c|c|}
\hline \multirow[b]{2}{*}{ Gene } & \multicolumn{2}{|c|}{ Flanking sequence (bp) } & \multirow[b]{2}{*}{ Del/trans ${ }^{\mathrm{a}}$} & \multirow[b]{2}{*}{ Efficiency $(\%)^{\mathrm{b}}$} \\
\hline & $5^{\prime}$ & $3^{\prime}$ & & \\
\hline $3 H N R$ & 469 & 414 & $5 / 15$ & 33.3 \\
\hline$L A E 1$ & 842 & 846 & $11 / 13$ & 84.6 \\
\hline PKS 179218 & 760 & 762 & $14 / 15$ & 93.3 \\
\hline ECP6 & 921 & 983 & $6 / 6$ & 100 \\
\hline FTR1 & 879 & 892 & $6 / 6$ & 100 \\
\hline
\end{tabular}

a Number of deletants/transformants (D/T).

${ }^{\mathrm{b}}$ Homologous recombination efficiency. deletion was performed using GoTaq DNA polymerase (Promega Corp., Madison, WI]). To verify insertion of the $H P H$ gene at the native $3 H N R$ locus, four primer pairs were used: primers NLC37/ NLC38 to confirm the presence of $\mathrm{HPH}$; TtrpCend/3HNR-F 3 and PtrpC/3HNR-R $\mathrm{R}_{3}$ to confirm correct insertion into the $5^{\prime}$ and $3^{\prime}$ flanks of $3 H N R$, respectively; and $3 \mathrm{HNR}-\mathrm{F}_{3} / 3 \mathrm{HNR}-\mathrm{R}_{3}$ to confirm expected size of insertion. Primer sequences are listed in Table 1.

In addition, Southern blot analysis of DNA from the WT and three of five confirmed $3 h n r$ mutants was performed. For this, genomic DNA of mutant and WT strains was isolated from lyophilized mycelia. Mycelia were ground in liquid nitrogen using a mortar and pestle, resuspended in extraction buffer $(150 \mathrm{mM}$ EDTA, $50 \mathrm{mM}$ Tris- $\mathrm{HCl}$ [pH 8.0], 1\% sodium lauryl sarkosyl, and proteinase $\mathrm{K}$ at $300 \mathrm{mg} / \mathrm{liter}$ ) and extracted once with an equal volume of Tris-saturated phenol, twice with phenol/chloroform/isoamyl alcohol (25:24:1), and twice with chloroform/isoamyl alcohol (24:1). DNA was precipitated with two volumes of cold $99.5 \%$ ethanol and 1/10 volume sodium acetate $(3 \mathrm{M})$ and dissolved in $400 \mu \mathrm{l}$ of Tris-EDTA (TE). Samples were treated with RNase $(10 \mu \mathrm{g} / \mu \mathrm{l})$ at $37^{\circ} \mathrm{C}$ for $1 \mathrm{~h}$. A second round of DNA purification was done as above. Finally, DNA was precipitated with 20\% (wt/vol) PEG 8000/2.5 M NaCl, spooled out, washed with $70 \%$ ethanol, air dried, and dissolved in an appropriate volume of TE.

For blotting, genomic DNA was digested with XhoI overnight at $37^{\circ} \mathrm{C}$, separated by electrophoresis in a $1 \%(\mathrm{wt} / \mathrm{vol})$ agarose gel, and transferred to a nitrocellulose membrane using standard protocols (26). A digoxigenin (DIG)-labeled probe was generated by PCR using primers NLC37/M13R to amplify the $H P H$ gene and the membrane hybridized to the labeled DNA. Hybridizing bands were detected using the DIG High Prime DNA Labeling and Detection Starter Kit II Direct Labeling and Detection System according to the manufacturer's instructions (Roche, Mannheim, Germany).

LAE1, PKS179218, ECP6, and FTR1. For confirmation of deletion of S. turcica LAE1, PKS179218, ECP6, and FTR1 genes, the same PCR primer strategies described above for $3 H N R$ were used (Supplemental Figure 1).

Virulence assays. Three-week-old 'W64A-N' or 'Pa91' maize plants were used to evaluate virulence of lae 1 and ecp6 mutants, respectively, as previously described (20). A spore suspension $\left(2 \mathrm{ml}\right.$ of $5 \times 10^{3}$ spores $/ \mathrm{ml}$ ) was spray inoculated on each plant. Diseased leaves were photographed at 8 (for lae1) or 9 (for ecp6) days postinoculation.

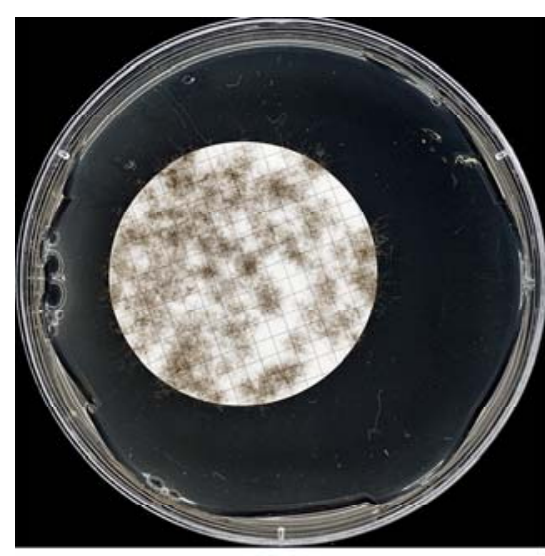

A

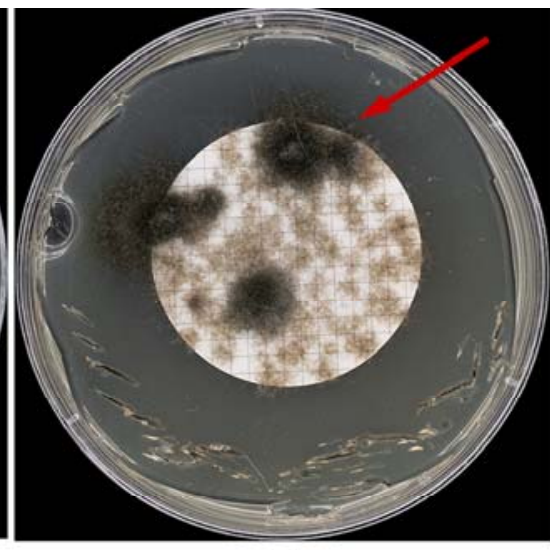

B

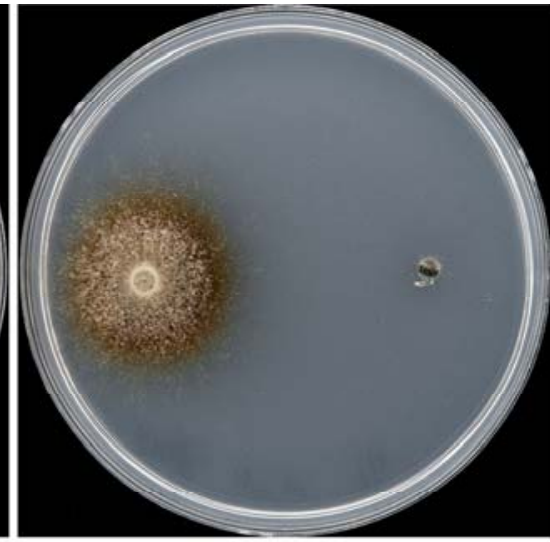

C

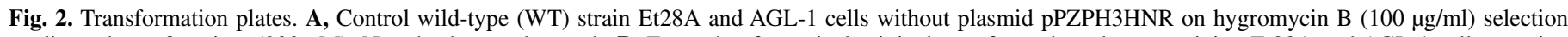

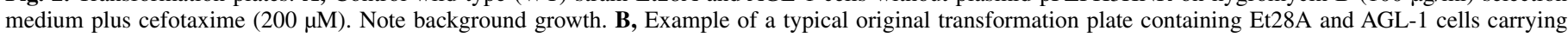

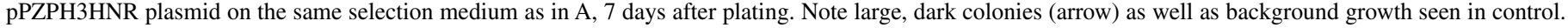

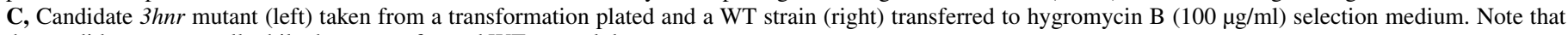
the candidate grows well while the untransformed WT control does not. 


\section{RESULTS AND DISCUSSION}

Strain selection. Strains Et28A (MAT1-1) and 52B (MAT1-2) were chosen from five candidate WT strains because they grew well, conidiated well, and were sensitive to hygromycin B. Level of sensitivity to hygromycin B was tested by growing strains on LCA plates supplemented with different concentrations of the antibiotic $(50,100,150,200,300,400,500,600,800$, or 1,000 $\mu \mathrm{g} / \mathrm{ml})$. Growth of Et28A and 52B was inhibited partly at 100 $\mu \mathrm{g} / \mathrm{ml}$ and completely at $200 \mu \mathrm{g} / \mathrm{ml}$. Other strains showed less sensitivity to hygromycin B. For selection of candidate transformants, $100 \mu \mathrm{g} / \mathrm{ml}$ was chosen.
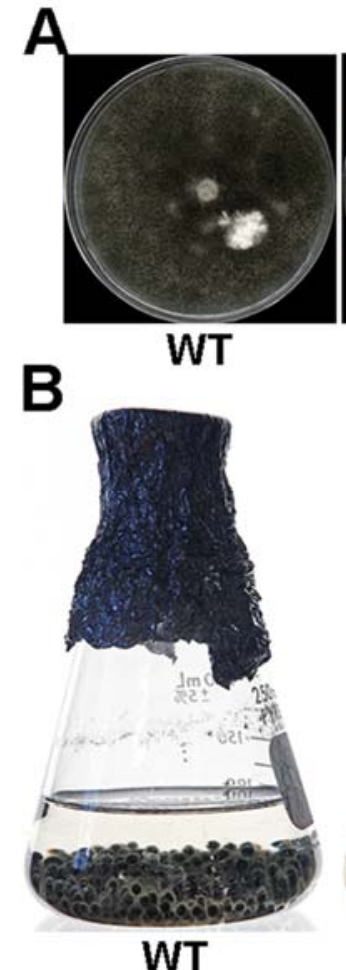

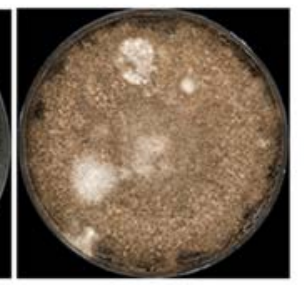

$3 h n r$

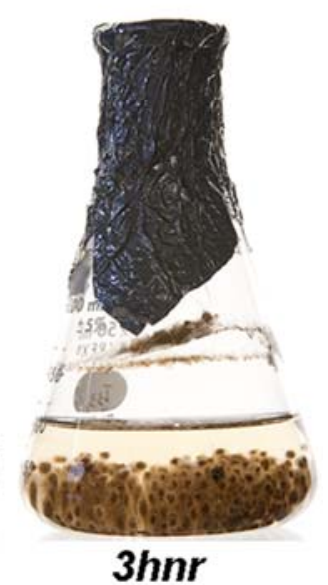

Fig. 3. Phenotype of 1,3,8-trihydroxynaphthalene reductase (3hnr) mutants compared with the wild type (WT). WT and mutant A, on lactose casein (LC) agar and $\mathbf{B}$, in LC liquid. Note that mutant is light brown, indicating a block in the melanin synthesis pathway.
Factors influencing ATMT efficiency in S. turcica. Germination conditions. Conidial germination rate was tested in triplicate in three different media-Fries (24), LC, and potato dextrose (29) - and Fries was the best. Conidia germinated for 0, 2, 6, 12, 18 , or $24 \mathrm{~h}$ were tried as starting material for transformation; transformants were obtained only with the 24-h materials even though a number of parameters, including varying the induction medium (below), co-cultivation conditions (below), and concentration of AS, were tried as discussed below.

Induction medium. Two different inducing media, IAM and IM, were tested. Transformants were obtained only with IAM, although IM had been reported to work previously (8) for random insertion in a different strain of $S$. turcica. The reason for this difference is unclear but may be related to strain differences.

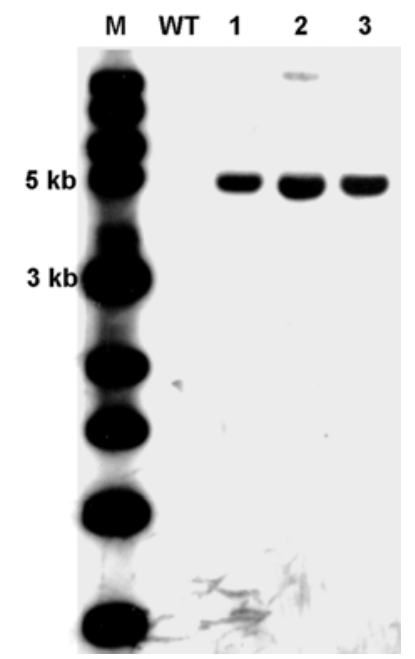

Fig. 5. Southern blot analysis of 1,3,8-trihydroxynaphthalene reductase (3hnr) mutants. Genomic DNA was cut with $\mathrm{XhoI}$, a restriction enzyme that does not cut in $H P H$, and separated on a $1.0 \%$ agarose gel by electrophoresis. DNAs were transferred to a nitrocellulose membrane and hybridized using a digoxigenin-labeled 1.1-kb fragment of $H P H$ as described in Materials and Methods. Lanes 1 to 3, DNA from transformants and unmarked lane is DNA from WT, wild type. Sizes of the 1-kb DNA ladder markers $(\mathrm{kb})$ are indicated on the left. When homologous integration has occurred, a hybridizing band of $\approx 5 \mathrm{~kb}$ is observed due to integration of the selectable marker. A band of $\approx 10 \mathrm{~kb}$ was also observed in one of the mutants (lane 2) indicating that a copy of $H P H$ also integrated somewhere other than at the $3 H N R$ locus. The WT lane doesn't have any hybridization signal due to lack of the $H P H$ gene.

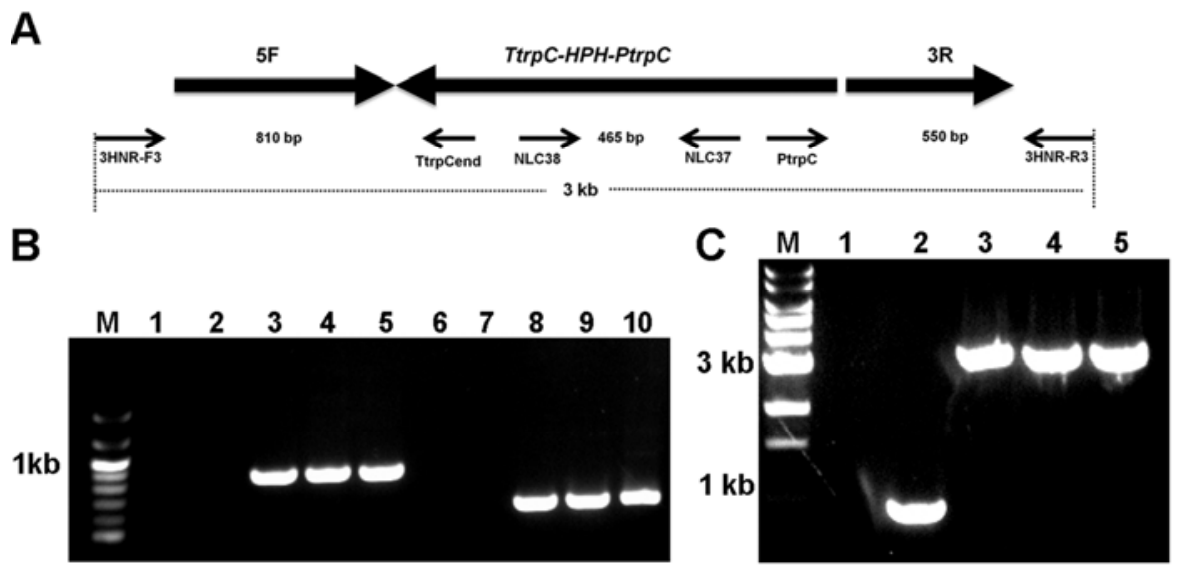

Fig. 4. Polymerase chain reaction (PCR) analysis of 1,3,8-trihydroxynaphthalene reductase (3hnr) mutants of Setosphaeria turcica. A, Schematic representation of the DNA used for transformation. $5 \mathrm{~F}=3 H N R-5 \mathrm{~F}$ flanking sequence of $3 \mathrm{HNR}, 3 \mathrm{R}=3 \mathrm{HNR}-3 \mathrm{R}$ flanking sequence of $3 \mathrm{HNR}$, PtrpC $=$ Aspergillus nidulans trpC promoter; $H P H$ is the hygromycin B resistance gene and TtrpC is the A. nidulans trpC terminator. 3HNR-F3, TtrpCend, NLC38, NLC37, PtrpC, and 3HNR-R3, are primers used for screening $3 h n r$ mutants (Table 1). B and C, PCR confirmation of $3 h n r$ mutants from three randomly selected transformants using primers B, 3HNR-F3/TtrpCend (lanes 1 to 5) and PtrpC/3HNR-R3 (lanes 6 to 10) and $\mathbf{C}, 3 \mathrm{HNR}-\mathrm{F} 3 / 3 \mathrm{HNR}-\mathrm{R} 3$. Lane M, NEB 1-kb DNA ladder marker; lanes 1 and 6, $\mathrm{H}_{2} \mathrm{O}$; lanes 2 and 7, DNA from wild type; lanes 3 to 5 and 8 to 10, DNA from transformants. Size of PCR product from the mutants matches the predicted size of $3 \mathrm{HNR}-5 \mathrm{~F}+H P H+3 \mathrm{HNR}-3 \mathrm{R}$, indicating replacement of the $3 H N R$ gene by hygB resistance gene at the $3 H N R$ locus. 
Agrobacterium cell density. Cell concentration $\left(\mathrm{OD}_{600}\right.$ value $)$ of AGL-1 after induction was also a key factor; no gene knockouts were obtained when the OD value was $<0.5$, although it was evident that $H P H$ was randomly inserted into the genome at lower cell densities (0.2 to $0.5 \mathrm{OD})$.

Plating conditions. The mixture of agrobacteria and fungal conidia was shaken in liquid medium for $48 \mathrm{~h}$ or plated immediately on a cellulose nitrate membrane. Transformants were obtained only when mixtures were plated immediately on membranes. Previous publications reported no success using this procedure (4). Varying the concentration of AS (200, 300, or
$500 \mu \mathrm{M})$ made no difference to transformation efficiency. Putative transformants grew faster than background growth on selection medium (Fig. 2). Overall transformation efficiency was $\approx 20 \pm$ 3 transformants per $1 \times 10^{6}$ starting conidia.

We did not succeed with protoplast transformation of strain Et $28 \mathrm{~A}$ or 52B. At least 20 protoplast transformation attempts executed in triplicate for each set of conditions, including several cell-wall-degrading enzymes such as Snailase, Driselase, lysing enzymes, Rhozyme, Cellulase, and Glucanex, were made without success. In some experiments, we did generate low numbers of protoplasts but inconsistently. Initially, we speculated that it may
A

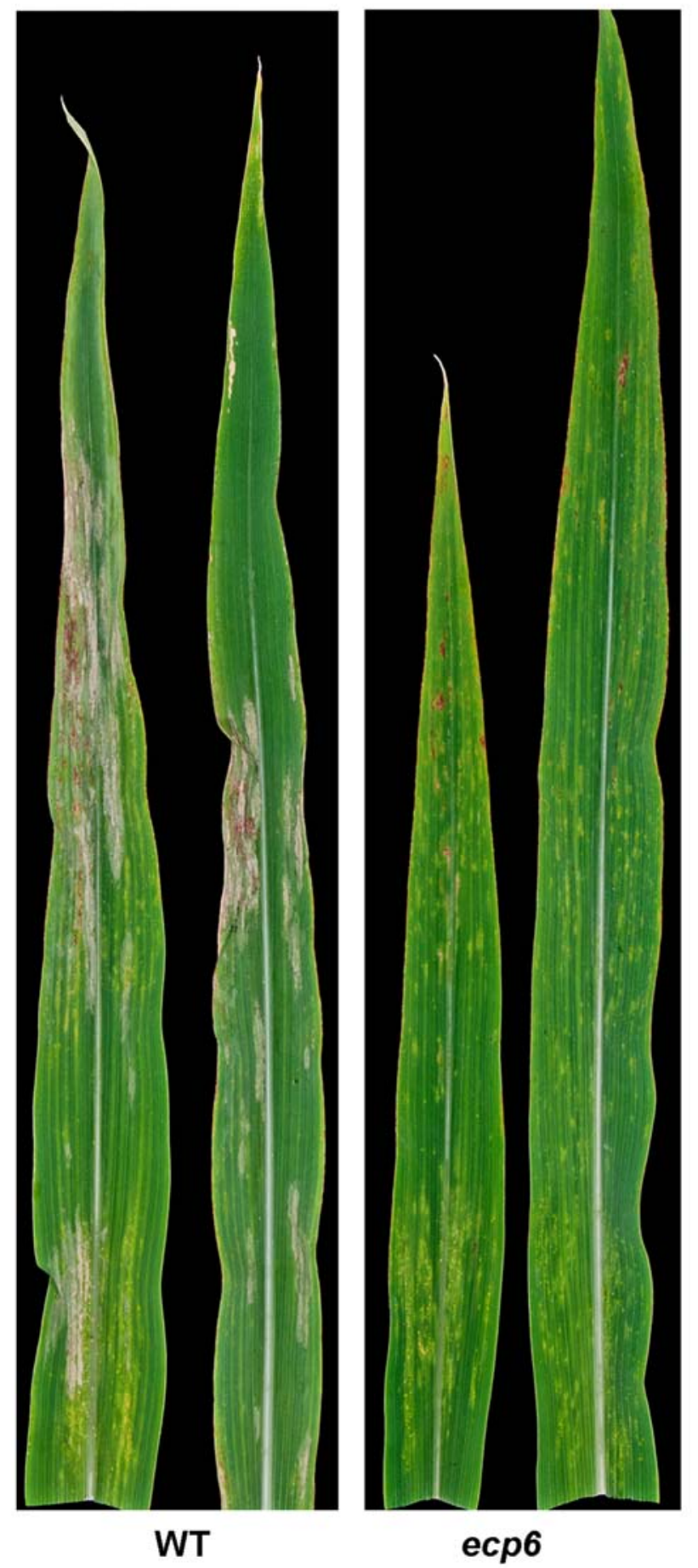

B

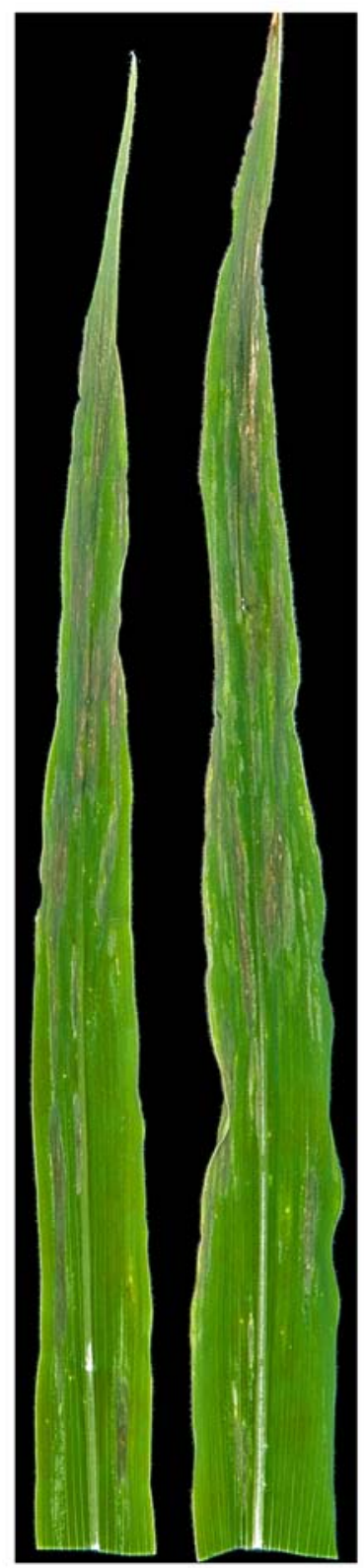

WT

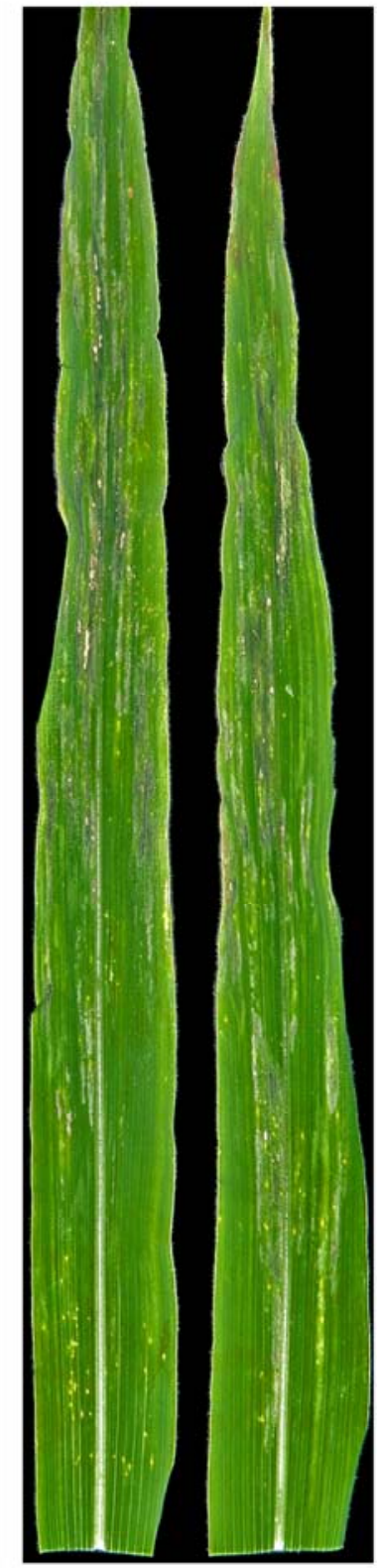

lae1

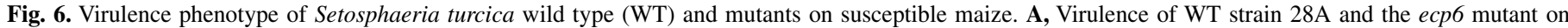

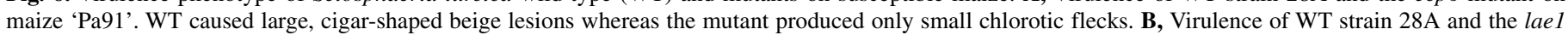
mutant on maize 'W64A-N'. Virulence of the mutant was similar to the WT. 
be difficult to obtain sufficient numbers of protoplasts because the fungus melanizes very quickly. However, using ATMT, we have since created an albino strain deleted for the polyketide synthase gene, $P K S 18$, required for melanin biosynthesis. Protoplasting attempts were no more successful with this mutant than with the pigmented strain. Thus, we speculate that there is something about the $S$. turcica cell wall composition that is recalcitrant to digestion by the battery of cell-wall-degrading enzymes we employed.

Verification of transformation and targeted integration. 3HNR. The $3 H N R$ gene in the melanin biosynthesis pathway was chosen as the initial target for deletion because mutants were expected to be brown and, thus, readily distinguishable from black WT colonies (Fig. 3). Hygromycin-B-resistant colonies obtained with ATMT were screened by PCR using primer pairs NLC37/NLC38, 3HNR-F 3 /TtrpCend, and PtrpC/3HNR-R 3 , which were expected to amplify products of 465,810 , and $550 \mathrm{bp}$, respectively, if the $3 H N R$ gene was deleted (Table 2). These three bands should be absent in the WT. Primer pair $3 \mathrm{HNR}-\mathrm{F}_{3} / 3 \mathrm{HNR}-$ $\mathrm{R}_{3}$ should amplify a product of $3,055 \mathrm{bp}$ in deletion strains and $942 \mathrm{bp}$ in the WT. According to PCR assays, 5 of 15 transformants screened were $3 h n r$ deletants when flanking sequences of 469 and $414 \mathrm{bp}$ were used for integration (Fig. 4). Thus, under these conditions, homologous recombination efficiency was $30 \%$.

Southern blot analysis of three independent transformants, determined by PCR to be $3 h n r$ mutants, confirmed that the $H P H$ gene had integrated at a single site in two of the three cases. In the two transformants, a single XhoI hybridizing band of $\approx 5 \mathrm{~kb}$ was detected in transformants but absent from the WT; in the third, the same band plus an additional band of $10 \mathrm{~kb}$, perhaps due to a second site insertion of the $H P H$ gene, were present (Fig. 5).

LAE1, PKS179218, ECP6, and FTR1. Verification of deletion of four additional genes was done by diagnostic PCR. Because the genome sequence of strain $28 \mathrm{~A}$ was available at the time these deletions were made (unlike for $3 H N R$ ), longer flanking sequences were readily available for constructions. Increasing the flanking region to $>700 \mathrm{bp}$ improved transformation efficiency dramatically from $\approx 30 \%$ to $>80 \%$ (Table 2 ). Three of these genes were deleted from strain $28 \mathrm{~A}$ while the fourth, FTRl, was deleted in strain 52B, all using the same protocols.

Thus, the ATMT method has proven to be robust for deletion of five different genes in two different field isolates and should be applicable to all field-collected and laboratory strains.

Virulence phenotypes on susceptible maize. The $3 \mathrm{hnr}$, lael, and ecp6 mutants and WT strain 28A were inoculated on susceptible maize W64A-N or Pa91 (for ecp6). Virulence phenotypes of the first two mutants were similar to those of the WT (Fig. 6). In contrast, inoculation with the ecp6 mutant caused a significant reduction in virulence to maize. At 9 days postinoculation, the WT strain produced long beige cigar-shaped lesions; in contrast, inoculation with the mutant did not elicit this type of lesion but, instead, produced tiny chlorotic flecks. This matches results of studies of this gene in other fungi (e.g., Cladosporium fulvum and Magnaporthe oryzae $(2,17)$.

Conclusions. The final recommended protocol is as follows. AGL-1-containing vector is grown at $28^{\circ} \mathrm{C}$ for 1 day in LB. The culture is diluted with IAM to $\mathrm{OD}_{600}=\approx 0.1$ to 0.15 and grown overnight to $\mathrm{OD}_{600}=0.6$ to 0.7 . An Et $28 \mathrm{~A}$ conidial suspension is germinated $24 \mathrm{~h}$ before mixing with an equal volume of induced A. tumefaciens. The mixture $(500 \mu \mathrm{l})$ is spread on a cellulose nitrate membrane (Whatman $0.45 \mu \mathrm{m}$ ) on top of IAM agar in the presence of AS $(200 \mu \mathrm{M})$ and incubated at 22 to $25^{\circ} \mathrm{C}$ for $48 \mathrm{~h}$. Membranes are transferred onto LCA plates containing cefotaxime $(200 \mu \mathrm{g} / \mathrm{ml})$ and hygromycin B $(100 \mu \mathrm{g} / \mathrm{ml})$. Plates are incubated at 22 to $25^{\circ} \mathrm{C}$ for 7 to 12 days until conidiogenesis. Candidate transformants are purified by picking single conidia and reselected on LCA medium containing the same concentrations of hygromycin $\mathrm{B}$ and cefotaxime.
To obtain high efficiency of targeted integration, flanking sequences that are $>700 \mathrm{bp}$ are suggested. This protocol appears robust, based on trials using the same transformation parameters and protocols with two different field isolates and five different genes and phenotypic screens, including virulence assays, for alterations from WT.

\section{ACKNOWLEDGMENTS}

This study was funded by a United States Department of Agriculture AFRI grant to B. G. Turgeon. C. Xue was supported by the China Scholarship Council. We thank K. Loeffler, Dept. of Plant Pathology \& Plant-Microbe Biology, Cornell University, for expert imaging.

\section{LITERATURE CITED}

1. An, G., Ebert, P., Mitra, A., and Ha, S., eds. 1988. Binary Vectors, Plant Molecular Biology Manual. Kluwer Academic Publishers, Dordrecht, The Netherlands.

2. Bolton, M. D., van Esse, H. P., Vossen, J. H., de Jonge, R., Stergiopoulos, I., Stulemeijer, I. J. E., van den Berg, G. C. M., Borrás-Hidalgo, O., Dekker, H. L., de Koster, C. G., de Wit, P. J. G. M., Joosten, M. H. A. J., and Thomma, B. P. H. J. 2008. The novel Cladosporium fulvum lysin motif effector Ecp6 is a virulence factor with orthologues in other fungal species. Mol. Microbiol. 69:119-136.

3. Bundock, P., Den Dulk Ras, A., Beijersbergen, A., and Hooykaas, P. J. J. 1995. Trans-kingdom T-DNA transfer from Agrobacterium tumefaciens to Saccharomyces cerevisiae. EMBO J. 14:3206-3214.

4. Cao, Z. Y., 2009 Characterization and function analysis of the genes involved in melanin biosynthesis pathway in the phytopathogenic fungus Setosphaeria turcica. Thesis, Agricultural University of Heibe, Baoding, China.

5. Chan, M. T., Lee, T. M., and Chang, H. H. 1992. Transformation of indica rice (Oryzae sativa L.) mediated by Agrobacterium tumefaciens. Plant Cell Physiol. 33:577-583.

6. Chung, C. L., Longfellow, J. M., Walsh, E. K., Kerdieh, Z., Van Esbroeck, G., Balint-Kurti, P., and Nelson, R. J. 2010. Resistance loci affecting distinct stages of fungal pathogenesis: Use of introgression lines for QTL mapping and characterization in the maize-Setosphaeria turcica pathosystem. BMC Plant Biol. 10:103.

7. Cooley, R., Shaw, R., Franklin, F., and Caten, C. 1988. Transformation of the phytopathogenic fungus Septoria nodorum to hygromycin B resistance. Curr. Genet. 13:383-389.

8. Degefu, Y., and Hanif, M. 2003. Agrobacterium tumefaciens-mediated transformation of Helminthosporium turcicum, the maize leaf-blight fungus. Arch. Microbiol. 180:279-284.

9. de Groot, M. J., Bundock, P., Hooykaas, P. J., and Beijersbergen, A. G. 1998. Agrobacterium tumefaciens-mediated transformation of filamentous fungi. Nat. Biotechnol. 16:839-842.

10. Dickman, M. 1988. Whole cell transformation of the alfalfa fungal pathogen Colletotrichum trifolii. Curr. Genet. 14:241-246.

11. Gu, S. Q. 2007. Cloning and functional analysis of STK genes regulating the growth, development and pathogenicity of Setosphaeria turcica. Thesis, Agricultural University of Heibe, Baoding, China.

12. Hajdukiewicz, P., Svab, Z. and Maliga, P. 1994. The small, versatile ppzp family of Agrobacterium binary vectors for plant transformation. Plant Mol. Biol. 25:989-994.

13. Henson, J., Blake, N., and Pilgeram, A. 1988. Transformation of Gaeumannomyces graminis to benomyl resistance. Curr. Genet. 14:113-118.

14. Kistler, H., and Benny, U. 1988. Genetic transformation of the fungal plant wilt pathogen Fusarium oxysporum. Curr. Genet. 13:145-150.

15. Liu, J. G., Wang, Y. H., Zhang, G. Z., Jia, H., and Dong, J. G. 2007. Agrobacterium tumefaciens-mediated transformation of Setosphaeria turcica. Acta Phytopathol. Sin. 37:675-678.

16. Lu, S. W., Lyngholm, L., Yang, G., Bronson, C., Yoder, O. C., and Turgeon, B. G. 1994. Tagged mutations at the Tox 1 locus of Cochliobolus heterostrophus using restriction enzyme-mediated integration. Proc. Natl. Acad. Sci. USA 91:12649-12653.

17. Mentlak, T., Kombrink, A., Shinya, T., Ryder, L. S., Otomo, I., Saitoh, H., Terauchi, R., Nishizawa, Y., Shibuya, N., Thomma, B. P. H. J., and Talbot, N. J. 2012. Effector-mediated suppression of chitin-triggered immunity by Magnaporthe oryzae is necessary for rice blast disease. Plant Cell. http://dx.doi.org/10.1105/tpc. 111

18. Michielse, C. B., Arentshorst, M., Ram, A. F., and Van Den Hondel, C. A. 2005. Agrobacterium-mediated transformation leads to improved gene replacement efficiency in Aspergillus awamori. Fungal Genet. Biol. 42:919.

19. Mullins, E. D., and Kang, S. 2001. Transformation: A tool for studying 
fungal pathogens of plants. Cell. Mol. Life Sci. 58:2043-2052.

20. Oide, S., Moeder, W., Krasnoff, S., Gibson, D., Haas, H., Yoshioka, K., and Turgeon, B. G. 2006. NPS6, encoding a non-ribosomal peptide synthetase involved in siderophore-mediated iron metabolism, is a conserved virulence determinant of plant pathogenic ascomycetes. Plant Cell 18(10):2836-2853.

21. Parsons, K. A., Chumley, F. G., and Valent, B. 1987. Genetic transformation of the fungal pathogen responsible for rice blast disease. Proc. Natl. Acad. Sci. USA 84:4161-4165.

22. Paz Z, García-Pedrajas, M. D., Andrews, D. L., Klosterman, S. J., BaezaMontañez, L., and Gold, S. E. 2011. One step construction of Agrobacterium-recombination-ready-plasmids (OSCAR), an efficient and robust tool for ATMT based gene deletion construction in fungi. Fungal Genet. Biol. 48:677-684.

23. Perkins, J. M., and Pedersen, W. L. 1987. Disease development and yield losses associated with northern leaf-blight on corn. Plant Dis. 71:940-943.

24. Pringle, R. B., and Braun, A. C. 1957. The isolation of the toxin of Helminthosporium victoriae. Phytopathology 47:369-371.

25. Rodriguez, R. J., and Yoder, O. C. 1987. Selectable genes for transformation of the fungal plant pathogen Glomerella cingulata $\mathrm{f}$. sp. phaseoli (Colletotrichum lindemuthianum). Gene 54:73-81.

26. Sambrook, J., and Russell, D. W., eds. 2001. Molecular Cloning: A Laboratory Manual. Cold Spring Harbor Laboratory Press, Cold Spring Harbor, NY.

27. Suarez, T., and Eslava, A. P. 1988. Transformation of phycomyces with a bacterial gene for kanamycin resistance. Mol. Gen. Genet. 212:120-123.

28. Sugui, J. A., Chang, Y. C., and Kwon-Chung, K. J. 2005. Agrobacterium tumefaciens-mediated transformation of Aspergillus fumigatus: An efficient tool for insertional mutagenesis and targeted gene disruption. Appl. Environ. Microbiol. 71:1798-1802.

29. Thompson, J. E., Fahnestock, S., Farrall, L., Liao, D. I., Valent, B., and Jordan, D. B. 2000. The second naphthol reductase of fungal melanin biosynthesis in Magnaporthe grisea: Tetrahydroxynaphthalene reductase. J Biol. Chem. 275:34867-34872.

30. Turgeon, B. G., Garber, R. C., and Yoder, O. C. 1985. Transformation of the fungal maize pathogen Cochliobolus heterostrophus using the Aspergillus nidulans amdS gene. Mol. Gen. Genet. 201:450-453.

31. Wu , X. B. 2008. Functional analysis of STK2 gene in mitogen-activated protein kinase cascade form Setosphaeria turcica. Thesis, Agricultural University of Heibe, Baoding, China. 